\title{
Reflection on Recycling of Waste Ceramics Under the Promotion of Green Development
}

\author{
Yanming Li \\ Guangzhou Fengwo Decoration Design Co., Ltd. \\ Guangzhou, China
}

\begin{abstract}
In this article, the author has studied the design concept of recycling waste ceramics. Under the background of promoting green development, through the discussion of the recycling of waste ceramics, the characteristics of waste ceramics have been analyzed. Combined with the concept of ecological design, organically linked with the regeneration design, the methods for recycling waste ceramics have been explored. It is hoped that the results of the research can help promote the collaborative progress of economic and social development and ecological environment protection, and create a good production and living environment for people.
\end{abstract}

Keywords-green development; waste ceramics; recycling; exploration and reflections

\section{INTRODUCTION}

Global environmental issues and social environmental issues can be understood as the influence of production and consumption systems on ecological balance. It is necessary to develop the society and economy, but the development should not bring great changes to the environment and should not endanger the ecological balance. "Environment and sustainable development" has become a global concern, a hot issue in today's society, and a serious problem for humanity. At present, consumers in modern society already have the concept of "ecofriendly". Apart from making products have general functions, the design and creation should pay more attention to ecological design. The packaging of products is not only for providing basic functions and making products looked beautiful, but also for bringing consumers happiness through their humanized and ecological design. The phenomenon of "following blindly" of consumersgradually disappeared, and the concept of "ecological journey" gradually emerged. This consumption trend also indirectly increases the possibility of recycling waste resources. Therefore, ecological sustainable design and low-carbon good-looking design have also been loved and welcomed by consumers. The recycling of waste resources is an environmental protection measure and an important way to realize the concept of green ecological design.

\section{The DESIGN IDEA OF RECYCLING WASTE CERAMICS}

\section{A. Overview of Waste Ceramics}

Today's industrialized production has also brought about more and more wastes, and the ceramic industry is no exception. In the large-scale industrial production of ceramics, a large number of waste ceramics is also produced: scraps, inferiors, wastes and so on. Waste ceramics have been fired at high temperatures and are difficult to degrade under natural conditions, causing severe pollution to the environment. If these waste ceramics can be reused, that will do great help to environmental protection and green development. Waste ceramics are common but inconspicuous. They are simple and practical. Their application in daily life is very extensive. Here we mainly mean some industrial products commonly used in life and work. We can not only use waste ceramics to create and design artworks, but also use waste ceramics to create functional daily-use industrial products to meet the needs of consumers; at the same time, we can also design daily-use industrial products which are humanized, comfortable, practical, healthy and beautiful and can lead the consumer demands.

\section{B. The Design Concept of Recycling}

To recycle waste resources, it is necessary to establish an industrial production model of "resources-products-waste resources-recycling-recycled resources-redesign-recycled products". The defective products or products whose life cycles have ended are used as the renewable resources for the next products, so that these waste resources are recycled. At the same time, it is necessary to reduce the recycling costs and processing difficulties of renewable resources, strengthen innovation and design, and extend the service time of products through a variety of ways to avoid premature and excessive waste of resources. There is also the recycling of discarded items, giving new life and value to waste products. Recycling is a manifestation of ecological design. Ecological design follows the principles of localization, conservation, naturalization, evolutionary style, participation of all, and unity between nature and humanity, emphasizing reduction, recycling, and reuse; It is required that environmental factors be taken into consideration at all stages of product development. And the impact on the environment is minimized throughout the product's life cycle, ultimately leading to a more sustainable production and consumption system. To sum up, mainly two aspects are included. First, from the perspective of environment protection, reduce resource consumption and achieve sustainable development. Second, from the perspective of business, reduce costs and potential risks to improve competitiveness. 


\section{ThOughts ON ReCYCLING OF WASTE CERAMICS}

In today's economic growth and social development approach aimed at efficiency, harmony, and sustainability, the recycling of waste ceramics is a new design concept and method for ecological design, which is worth our in-depth study. Waste recycling has attracted widespread recognition and attention from all countries in the world and has formed a way to promote green development. The idea of recycling waste ceramics also provides designers with new inspirations and thinking points. As a designer, we are also obliged to assume the responsibility of creating an eco-design that is beneficial to humans to form a production model that protects the environment and promotes recycling of resources and to create a lifestyle of green development as well as green ecology.

\section{A. Material Replacement Method}

The material replacement method means that the materials are replaced, that is to say, some materials are replaced with a waste ceramic. Waste ceramics have different material characteristics: ceramic features, used traces, cultural memories, etc. Unique works designed by using material replacement methods allow the continuation of the life of waste ceramics, and have the function of displaying various product materials. Designers can use unique traces and patterns on discarded ceramics from different geographies and eras to process them and turn ordinary waste ceramics into unique design materials. Moreover, it will be better to replace some familiar materials of the products with appropriate waste ceramic materials that have been taken out according to differences in the location of the materials and handicrafts. In combination with the aesthetic sense and practicality, the design of each new product is slightly different. In this way, not only can the new life of waste materials be recycled, but it also makes new products have a better market.

The replacement of spent ceramic recycling materials requires attention to the physical characteristics of them. They are fired at medium or high temperature and are the materials with the highest stiffness and highest hardness; it is necessary to pay attention to the surface texture of waste ceramics. They have rich and colorful glaze and rich texture. There are different kinds of colors and texture, such as blue flowers with white background, western red, apple green, yellowish, bronze fish roe, black purple, crackle shape, crystal shape and so on; pay attention to the sculptural characteristics of the waste ceramic materials. They have various shapes, such as sheet, arc, and granules and so on. According to these characteristics of abandoned ceramics, material replacement can continue the life of abandoned ceramics and create unique and new ecological design works.

\section{B. Upgrade and Reconstruction Method}

In modern times, the innovations of various works of art and commodities are focused on the sustainability of products, the improvement of product concepts, the recycling of materials, the development of new materials, and so on. Their innovations are not limited to production--sales- usingdiscarding. Beyond this process, it is essential to take the responsibility for the ecological environment, which is an even more important consideration today. Therefore, designers must not ignore the waste caused by various natural disasters in our daily lives or all kinds of human-caused garbage. They are the means to realize the environmental protection by recycling wastes, and are also one of important ways to realize the ecological design concept.

The first is the recycling of various waste ceramics produced in life. As the variety of products in life continues to increase and various products continue to be refurbished, different design modalities have emerged, which has led to the vigorous development of the entire design field, further improving the lives and spending habits of people around the world, and giving people more choices. Under this background, designers use various waste ceramics in our lives as design materials to highlight the characteristics of them, such as waste ceramics features, waste marks and so on. These characteristics will be processed in an artistic way to create recycled products that are eco-friendly and demonstrate to consumers a new concept of consumption. New products designed by using various kinds of waste ceramics in life give consumers a felling of familiarity but novelty, unfamiliarity but intimacy, causing the desire of consumers to purchase. As a result, both the aim of promotion and spreading concept of ecological protection are realized, thus forming a unique design style, highlighting the unique aesthetic taste, and guiding the significance of consumer's environmental protection so that these materials have become an important material visual carriers and communication medium for contemporary ecological design.

The second one is the re-use of various waste ceramics in life. Because the sustainability of the ecological environment develops when it does not exceed the capacity of the regeneration of the ecological environment, human development should maintain balance with the carrying capacity of the earth to ensure that the human living environment can be sustained. Only in this way can the human living environment be sustained. But nowadays, on the contrary, the renewal of ecological and environmental systems is far behind the current human destructive development of the environment. The combination of science and technology, art and culture can be a powerful driving factor for the further development of society, economy and culture. In the field of design, designers need to take on this responsibility, link ecodesign and consumers, and guide people in the concept of daily consumption to create a new generation of sustainable eco-products.

In general, recycling is the innovative design of material structure, color, attributes, surface features, etc. In the design process, it cannot produce environmental damage, pollution and other similar acts. In addition, as far as possible, designers should preserve the cultural memory of waste materials and try to give these waste ceramics a new sense of form, new vitality. Relying on the artistry, the concept of ecological design should be expressed just rightly to meet the requirements of conveying product information and the concepts of protecting products accompanied by ecological design idea of waste resources recycling to promote green development. 


\section{Material Mashup}

People often meet some innovative objects. These objects show a refreshing visual image in various ways, constantly attracting the people's eyes and mind. The design of material mashup is such a phenomenon, which brings a new trend of creation for design. From the color mashup of appearance design to the mashup of material design, the matching collision of different elements not only brings endless sense of art and imagination, but also adds more beauty to life. The recycling of waste ceramics can be as the medium of art expression through material mashup. Abundant materials make artistic expression more diversified and personalized, and design effect become stronger. In the material mashup design, how can the recycling of waste ceramics be achieved between arts and business, and between cost and environmental protection? The designer should better utilize the rejected materials to create and express themselves.

In the age of scarce resources, in the surging of artistic ideological trends, how designers position the direction of art has an important influence on the sustainable development of today's society, the humanized design and the construction of ecological city. If the height of both harvest of art and business, and cost and environmental protection is really achieved, the material mashup is worth exploring. It does not make the abundance of materials become the flooding of arts, but the real care of commercial design. Meanwhile, we make an exploratory research on the application of material mashup design language symbols in the design and application from the perspective of philosophy, design methodology and ecology.

We use techniques to mix and match materials to optimize the disadvantages of waste materials, highlight material characteristics, and enhance design taste. Mashup can produce contrast, and contrast can generate beauty. Therefore, under the premise of promoting green development, we must strengthen the mashup design of waste ceramics and other materials, pursue the aesthetic taste of art form and optimization of process to enhance the visual beauty of design, tactile comfort of design and sense of smell and taste of design, and create different ecological design works with waste materials.

\section{CONCLUSION}

Today, with the promotion of green development and the concept of ecological design, recycling of waste ceramics is a very promising design research and responsibility research. Under the new ecological design environment that constantly promotes the design trend of waste resource recycling around the world, it is very necessary to study the recycling of waste ceramics. It not only brings designers a new design space, but also fully embodies the ecological concept of recycling of waste resources, and creates a variety of products that are visible at any time, truly healthy and humanized. It can also promote green development, circular development, low carbon development, and form the spatial pattern, industrial structure, production mode and life style of saving resources and protecting the environment, to achieve the life style of green development.

\section{REFERENCES}

[1] Ye Changyu. Discussion on Feasibility of Comprehensive Utilization of Waste Ceramics [J]. Energy and Environment, 2014, 01: 92-93+95. 叶 长裕.废弃陶瓷综合利用可行性探讨 [J].能源与环境, 2014, 01：92$93+95$.

[2] Li Quanheng. Innovative Design of "Reuse of Waste" in Design of Home Decorations [J]. Design, 2014, 07: 190-191. 李全恒.家居饰用品 设计中“废弃物再利用”创新设计[J].设计，2014，07：190-191.

[3] Tan Li, Yu Feng, Chen Xuewen. Recycling of Ceramic Wastes as Resources [J]. China Ceramic Industry, 2011, 18( 3): 21-25. 谭丽, 余峰，陈学文. 陶瓷废弃物资源化利用之浅谈 $[\mathrm{J}]$. 中国陶瓷工 业, 2011，18( 3): 21-25.

[4] Quanheng Li. Analysis on the Sustainability of Home Supplies Design [M]. ICASSEE 2017, ISBN(on-line):978-94-6252-438-5 , 2017 , 11: $277-279$.

[5] Liu Caizhi, Shen Ta, Li Rong. Discussion on the Artistic Form and Development of Contemporary Domestic Ceramics from the Perspective of Art Morphology [J]. China Ceramics, 2015, 12: 102-104 刘才志, 沈塔, 李榕.从艺术形态学谈当代日用陶瓷的艺术形式与 发展 $[\mathrm{J}]$.中国陶瓷，2015，12：102-104.

[6] [Italy] Vezzoli,C., (Italy) Manzini,E., Liu Xin, Yang Hongjun, Qin Jingyan. Design for Environmental Sustainability [M]. Beijing: National Defense Industry Press, 2010.10. 维佐里(Vezzoli,C.), [意]曼齐尼 (Manzini,E.).刘新, 杨洪君, 覃京燕,译.环境可持续设计[M].北京: 国防工业出版社，2010.10. 